\title{
BMJ Open Body mass index, waist-to-hip ratio and cognitive function among Chinese elderly: a cross-sectional study
}

\author{
Tao Zhang, ${ }^{1}$ Rui Yan, ${ }^{1}$ Qifeng Chen, ${ }^{2}$ Xuhua Ying, ${ }^{3}$ Yujia Zhai, ${ }^{1}$ Fudong Li, ${ }^{1}$ \\ Xinyi Wang, ${ }^{1}$ Fan He, ${ }^{1}$ Chiyu Ye, ${ }^{1}$ Junfen Lin ${ }^{1}$
}

To cite: Zhang T, Yan R, Chen $Q$, et al. Body mass index, waist-to-hip ratio and cognitive function among Chinese elderly: a crosssectional study. BMJ Open 2018;8:e022055. doi:10.1136/ bmjopen-2018-022055

- Prepublication history for this paper is available online. To view these files, please visit the journal online (http://dx.doi. org/10.1136/bmjopen-2018022055).

Received 1 February 2018 Revised 7 September 2018 Accepted 12 September 2018

Check for updates

(c) Author(s) (or their employer(s)) 2018. Re-use permitted under CC BY-NC. No commercial re-use. See rights and permissions. Published by BMJ.

${ }^{1}$ Zhejiang Provincial Center for Disease Control and Prevention, Hangzhou, Zhejiang, China ${ }^{2}$ Shaoxing Center for Disease Control and Prevention,

Shaoxing, Zhejiang, China

${ }^{3}$ Yuhuan Center for Disease Control and Prevention, Taizhou, Zhejiang, China

Correspondence to

Dr Junfen Lin;

zjlinjunfen@163.com

\section{ABSTRACT}

Objectives To investigate the associations between body mass index (BMI), waist-to-hip ratio (WHR) and cognitive function among Chinese elderly.

Design Cross-sectional study.

Setting Community.

Participants Data were obtained from the baseline survey of a community-based cohort in Zhejiang Province, and 9326 persons aged 60 years and older were enrolled. Primary outcome measures We investigated the association between BMI and cognition, and then explored the association between WHR and cognition across different quartiles of BMI.

Results A sample of 9087 persons was used in this study, including 4375 men and 4712 women. Higher WHR increased cognitive impairment risk in those with BMl $>25.3 \mathrm{~kg} / \mathrm{m}^{2}$ (OR (per 0.1 increase) $1.39 ; 95 \% \mathrm{Cl} 1.13$ to 1.70). No statistically significant association was found in other BMI categories.

Conclusions Higher WHR could increase the risk of cognitive impairment among elderly with $\mathrm{BMl}>25.3 \mathrm{~kg} / \mathrm{m}^{2}$. Our results suggest that it could be of benefit to the elderly with high BMI to control WHR.

\section{INTRODUCTION}

Cognitive impairment is an important health issue in the elderly. According to Alzheimer's Disease International (ADI), ${ }^{1}$ an estimated 46.8 million people currently have dementia in the world, the most well-known form of cognitive impairment, and this number will rise to 131.5 million in 2050. ADI estimated over 9.5 million people with dementia in China which was $20 \%$ of the total number of dementia cases in the world. By 2030, the number of people living with dementia in China is expected to rise to over 16 million. The incidence of dementia in people aged 60 years and older is 9.87 cases per 1000 personyears in China, ${ }^{2}$ and the situation of cognitive impairment would be more serious. ${ }^{3}$

Obesity was normally recognised as an influence factor of dementia. ${ }^{45}$ The possible reasons included inflammation and $\beta$-amyloid metabolism which had been shown to

\section{Strengths and limitations of this study}

The strength of this study was the in-depth analysis of the association between waist-to-hip ratio and cognitive impairment across different body mass index categories.

- High-fat diet, which is an important influence factor for cognitive function, was not included in this study.

- Since this was a cross-sectional study, caution would be needed when generalising the present findings.

be linked to obesity. ${ }^{6}$ However, studies on the association between BMI and cognitive impairment in the elderly have shown conflicting results: both positive and negative association have been reported. ${ }^{7-11}$ There is a limitation of BMI when comparing individuals with the same weight and height but different body fat mass. BMI is affected by both fat and fat-free mass which may have opposite effects on health. ${ }^{12}$ Using BMI as a surrogate for obesity may be particularly problematic in the elderly due to the effect of ageing on fat distribution. ${ }^{13}$ Waist-to-hip ratio (WHR), as a proxy for body fat distribution, would be a complementary indicator in health-related studies for the elderly. It has been reported that high WHR was associated with adverse health outcomes independent of BMI. ${ }^{14}{ }^{15}$ Actually, high WHR could increase death even with normal BMI. ${ }^{16} 17$ Therefore, it would be necessary to evaluate the effect of WHR when BMI was within a certain range.

However, to our knowledge, studies evaluating the association between BMI-specific WHR and cognitive impairment in a large Chinese elderly population were lacking. To help shed light on this area, we investigated the associations between BMI, WHR and cognitive impairment among Chinese aged 60 years and older. 


\section{MATERIALS AND METHODS}

\section{Study population}

The present study used data collected from the baseline survey of a community-based cohort study focusing on ageing and health problems among the elderly in Zhejiang province, China, since 2014. In brief, 6 out of 90 counties were randomly selected from Zhejiang province, with at least 1500 participants randomly recruited in each county for participation in 2014. Inclusion criteria were as following: (1) permanent residents who lived for over 6 months in the past year, (2) aged 60 years and above. Exclusion criterion was an inability to complete the interview due to physical disability. Finally, 9326 subjects were enrolled, with a response rate of $76 \%$. During the baseline survey, we performed questionnaire-based interview, physical examinations and laboratory tests for each participant. A total of 239 participants were excluded because of missing values in age, Chinese language version of the Mini-Mental State Examination (MMSE) score, or BMI, leaving 9087 available for analyses.

\section{Cognitive function}

Cognitive function was determined by MMSE which included 30 items. The maximum score of MMSE is 30, and higher scores indicate better cognitive function. According to Wang et al, the questionnaire of MMSE has good reliability and validity as an instrument to detect cognitive impairment among Chinese. ${ }^{18}$ The cut-off score of cognitive impairment is education-specific: $17 / 18$ for illiteracy, 20/21 for people with primary education level, 24/25 for people with higher than primary education level. ${ }^{19}$

\section{Body mass index}

Body mass index (BMI; $\mathrm{kg} / \mathrm{m}^{2}$ ) was calculated as a person's body weight (in kilograms) divided by the square of the body height (in metres). Body weight and height were measured by digital weight and height scale, respectively. All the participants were asked to remove shoes, heavy clothing and hats prior to height and weight measurements, and had the participants stand straight with heels together, legs straight and looking straight ahead.

\section{Waist-to-hip ratio}

Waist circumference was measured midway between the lower rib margin and the iliac crest, with a soft cloth tape measure. Hip circumference was measured at the level of the widest circumference over the greater trochanters, with a soft cloth tape measure. In the baseline survey, waist circumference and hip circumference were measured twice, and the difference of two measured values was restricted in $\pm 2 \mathrm{~cm}$. WHR was calculated as a person's waist circumference divided by the hip circumference. In this study, waist circumference and hip circumference were calculated as the mean of two measured values.

\section{Covariates}

Covariates were collected by face-to-face interview with questionnaire, including: age, race, education level (self-reported), marital status (self-reported), economic status (self-reported), smoking (self-reported), alcohol drinking (self-reported), physical exercise (activities which were carried out to sustain or improve health and fitness in one's spare time), hypertension (diagnosed by doctors), diabetes (diagnosed by doctors), coronary heart disease (diagnosed by doctors) and depressive symptom. Depressive symptom was determined using the Patient Health Questionnaire-9 scale. Those who scored 5 or above were defined as depression. ${ }^{20}$

\section{Statistical analysis}

Descriptive statistics were applied to illustrate the sociodemographic and health characteristics of the enrolled participants. Differences of the characteristics across different cognitive status groups were assessed by Student's t-test for continuous variables, and by $\chi^{2}$ test for categorical variables. Logistic regressions were used to examine the associations between BMI, WHR and cognitive impairment. BMI was evaluated as a categorical variable, divided by quartiles. WHR was evaluated under different BMI levels. Both BMI and WHR were assessed by three logistic models. In the basic model (model 1), no covariate was included when assessing the association between BMI and cognitive impairment, and BMI was adjusted when assessing the association between WHR and cognitive impairment. Model 2 was based on model 1, with additional adjusting for sociodemographic variables (age, sex, nation, education, marital status and family economics). Model 3 was based on model 2, with additional adjustments of lifestyles (smoking, drinking and physical exercise) and health variables (hypertension, stroke and depression).

All statistical analyses were performed by SAS V.9.4 (SAS Institute), and two-tailed $p$ value $<0.05$ was considered statistically significant.

\section{Patient and public involvement}

No patients were involved in setting the research question or the outcome measures, nor were they involved in developing plans for design or implementation of the study. No patients were asked to advise on interpretation or writing up of results. There are no plans to disseminate the results of the research to study participants or the relevant patient community.

\section{RESULTS}

\section{Sociodemographics and health characteristics}

Of the 9087 subjects, 1339 (14.7\%) were defined as cognitive impairment by MMSE. The mean age of all subjects was $69.8( \pm 8.3)$. More than a half $(51.9 \%)$ were female. Among the subjects with cognitive impairment, the mean MMSE score was $13.6( \pm 5.1)$, while the mean score was $25.8( \pm 3.1)$ in normal cognition group. The mean values of BMI and WHR were 22.7 $\pm 3.6,0.9 \pm 0.1$, respectively, in the cognitive impairment group, and the mean values were $23.3 \pm 3.3,0.9 \pm 0.1$, respectively, in normal cognition 
Table 1 Sociodemographics and health characteristics of 9087 participants by cognitive status

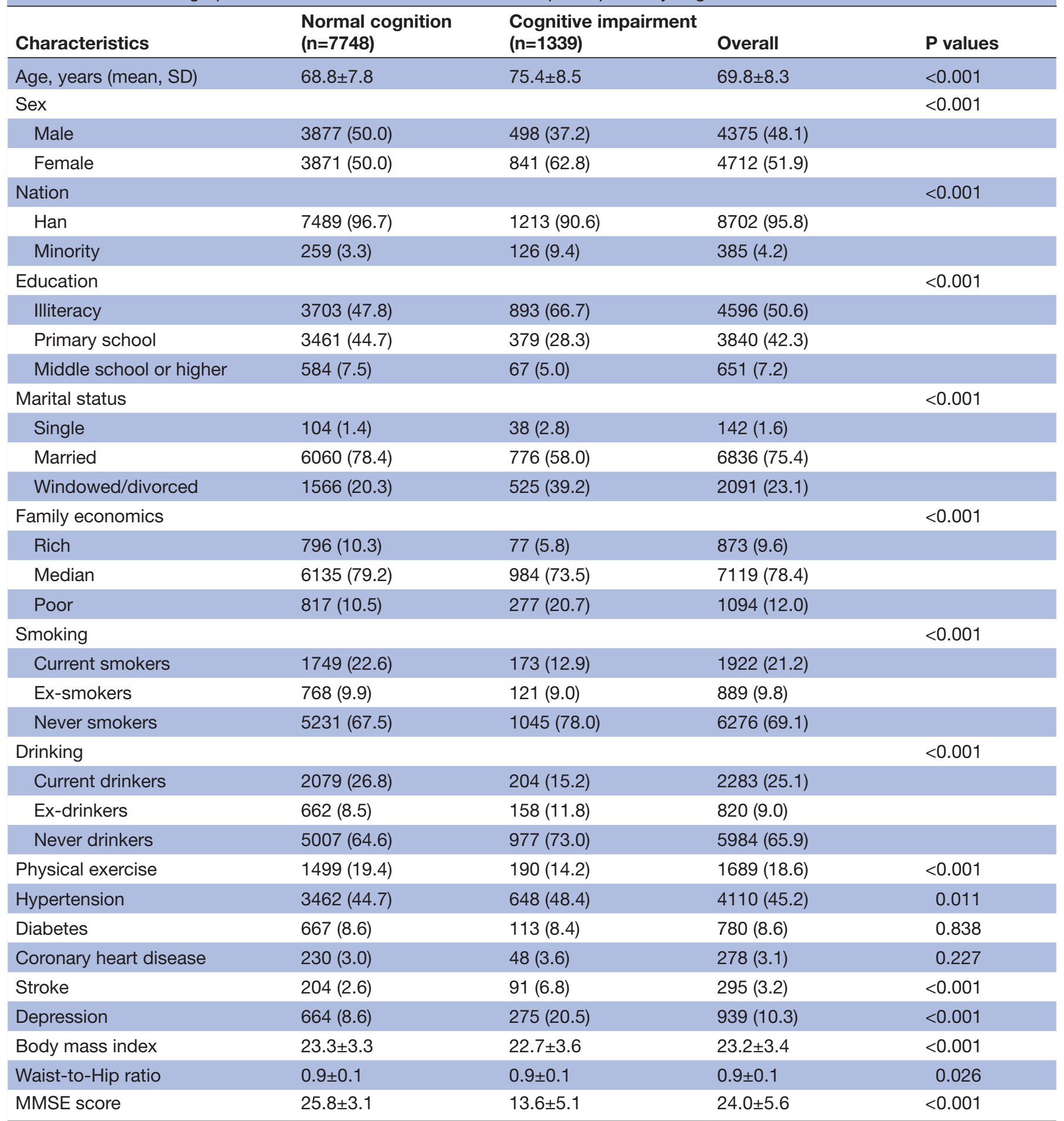

MMSE, Mini-Mental State Examination.

group. Differences of BMI and WHR between the two groups were both statistically significant. The subjects with cognitive impairment tended to be older, female, minority ethnic group, without physical exercise, with hypertension, with stroke, with depression. Also, cognitive impairment was associated with education, marital status, family economics, smoking and drinking. More details are shown in table 1 .
Association between BMI and cognitive impairment

The mean MMSE scores were calculated by quartiles of BMI. Subjects in the highest BMI quartile category had the highest mean MMSE score (24.36 \pm 5.28$)$, and those in the lowest quartile category had the lowest mean MMSE value (23.33 \pm 5.94$)$. Compared with the second quartile of BMI, the OR of the lowest quartile was $1.42(95 \%$ CI, 1.21 to 1.67$)$, the OR of the highest quartile was $0.86(95 \%$ 
Table 2 Association between body mass index and cognitive impairment

\begin{tabular}{|c|c|c|c|}
\hline \multirow[b]{2}{*}{$\begin{array}{l}\text { Quartiles of body mass } \\
\text { index, } \mathrm{kg} / \mathrm{m}^{2}\end{array}$} & \multicolumn{3}{|l|}{ OR (95\% Cl) } \\
\hline & $\begin{array}{l}\text { Model } 1^{*} \\
(n=9087)\end{array}$ & $\begin{array}{l}\text { Model 2† } \\
(\mathrm{n}=9068)\end{array}$ & $\begin{array}{l}\text { Model 3‡ } \\
(n=9068)\end{array}$ \\
\hline$>20.8-22.9$ & 1 & 1 & 1 \\
\hline$>22.9-25.3$ & 0.92 (0.77 to 1.08$)$ & 1.02 (0.85 to 1.22$)$ & $1.02(0.85$ to 1.22$)$ \\
\hline
\end{tabular}

*No covariate was included.

†Adjusted for age, sex, nation, education, marital status and family economics.

‡Based on model 2, model 3 was further adjusted for smoking, drinking, physical exercise, hypertension, stroke and depression.

CI, 0.72 to 1.02 ) and the third quartile had an OR value of 0.92 (95\% CI, 0.77 to 1.08). In model 3, the OR of Q1 BMI was close to being statistically significant, and these results were essentially unchanged after adjustment for more covariates (table 2).

\section{Association between WHR and cognitive impairment}

We detected two-way interaction between BMI and WHR, and the result was statistically significant $(\mathrm{p}=0.002)$. Further, the association between WHR and cognitive impairment was assessed under each BMI group. Under the lowest BMI group, the association between WHR and cognitive impairment was not statistically significant. Similar results were found in the second and third quartiles of BMI. In the highest BMI group, each 0.1 higher WHR corresponded to a 1.39-fold higher risk of cognitive impairment in the basic model. The OR value remained significant after adjusting for more covariates in model 2 and model 3 which were 1.36 (95\% CI 1.10 to 1.69 ) and 1.37 (95\% CI 1.10 to 1.71 ), respectively (table 3 ).

\section{Association between waist circumference and cognitive impairment}

Similarly, we assessed the associations between waist circumference and cognitive impairment within various BMI levels. When BMI, age, sex, nation, education, marital status, family economics, smoking, drinking, physical exercise, hypertension, stroke and depression were controlled, each 1-unit higher waist circumference corresponded to a 1.02-fold higher risk of cognitive impairment among the elderly with BMI $>22.9 \mathrm{~kg} / \mathrm{m}^{2}$ (table 4 ).

\section{DISCUSSION}

In this cross-sectional study of 9087 Chinese elderly aged 60 years and older, we investigated the associations between BMI, WHR and cognitive impairment risk. We found that each 0.1-unit increase in WHR corresponded to 1.37 (1.10-1.71) evaluated cognitive impairment risk in high BMI $\left(>25.3 \mathrm{~kg} / \mathrm{m}^{2}\right)$ group in the fully adjusted model (model 3).

In our study, compared with Q2 BMI $(>20.8-22.9 \mathrm{~kg}$ / $\left.\mathrm{m}^{2}\right)$, Q1 BMI $\left(\leq 20.8 \mathrm{~kg} / \mathrm{m}^{2}\right)$ was a risk factor for cognitive impairment, while Q4 BMI tended to be a protective factor, though not statistically significant. In previous studies, some reported that high BMI tended to be a risk factor for cognitive decline, ${ }^{9-11}$ while others observed a negative association between high BMI and cognitive function. ${ }^{458}$ The inconsistency suggests the complex relationship between BMI and cognitive function.

Zhou et $a l^{21}$ suggested that subjects who were both with obesity and dementia had a high mortality rate which might very likely remove those with high BMI and dementia, and leave moderate or severe dementia subjects with low BMI, thus enforce the association

Table 3 Association of waist-to-hip ratio (per 0.1 increase) with cognitive impairment under different body mass index groups

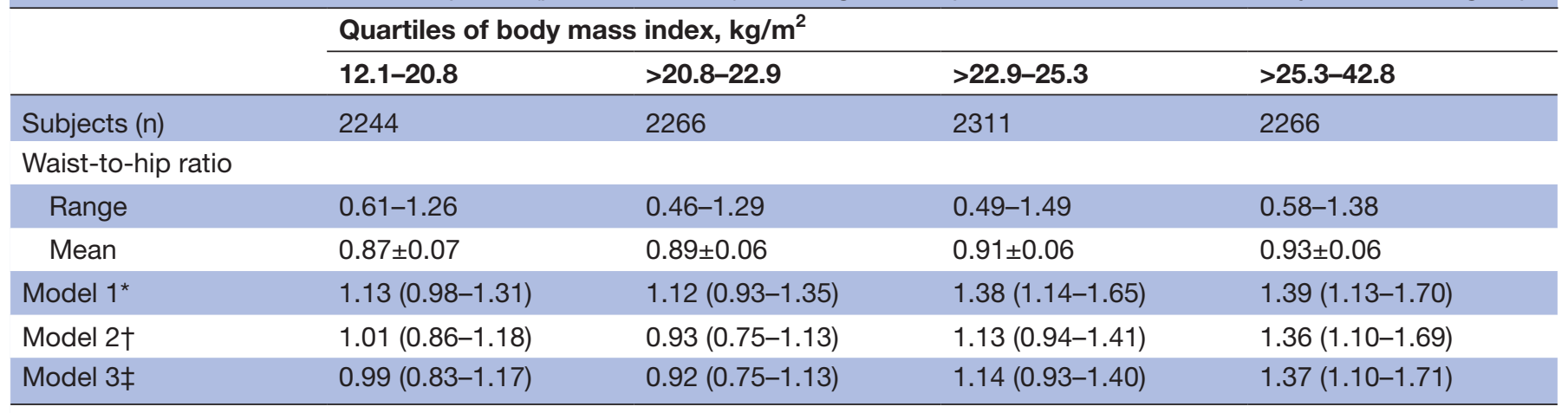

${ }^{*}$ Adjusted for body mass index.

†Based on model 1, model 2 was further adjusted for age, sex, nation, education, marital status and family economics.

łBased on model 2, model 3 was further adjusted for smoking, drinking, physical exercise, hypertension, stroke and depression. 
Table 4 Association of waist circumference with cognitive impairment under different body mass index groups

Quartiles of body mass index, $\mathrm{kg} / \mathrm{m}^{2}$

\begin{tabular}{lllll} 
& 12.1-20.8 & $\mathbf{2 0 . 8 - 2 2 . 9}$ & >22.9-25.3 & >25.3-42.8 \\
\hline Subjects $(n)$ & 2244 & 2266 & 2311 & 2266 \\
Model 1* $^{*}$ & $1.03(1.01-1.05)$ & $1.03(1.01-1.05)$ & $1.04(1.02-1.06)$ & $1.03(1.01-1.04)$ \\
Model 2† & $1.02(1.001-1.04)$ & $1.02(0.995-1.03)$ & $1.03(1.01-1.05)$ & $1.02(1.01-1.04)$ \\
Model 3† & $1.01(0.996-1.03)$ & $1.01(0.993-1.03)$ & $1.02(1.004-1.05)$ & $1.02(1.01-1.04)$ \\
\hline
\end{tabular}

${ }^{*}$ Adjusted for body mass index.

†Based on model 1, model 2 was further adjusted for age, sex, nation, education, marital status and family economics.

¥Based on model 2, model 3 was further adjusted for smoking, drinking, physical exercise, hypertension, stroke and depression.

between BMI and dementia. Assuming the survivor bias existed, the observed association between high BMI and cognition impairment would be biased towards the null, and such bias would be even more serious in cross-sectional study if it exists. Nevertheless, the hypothesis is not enough to explain the relationship between low BMI and cognitive impairment. Furthermore, several cohort studies reported that both persons with low BMI and persons with high BMI had lower cognitive functions in later life. ${ }^{22-26}$

Among the participants of this study, the mean value of WHR tended to increase within the higher BMI group. We observed a strong positive association between WHR and cognitive impairment risk under Q4 BMI $(>25.3 \mathrm{~kg} /$ $\mathrm{m}^{2}$ ) group. The association remained after adjusting for covariates. Similar results were observed when evaluating the association between waist circumference and cognitive impairment. These findings led us to speculate that body fat and muscle had a reverse effect on cognition. Adipokines might be a link between body fat and dementia. Adipokines include hundreds of polypeptides secreted by the cells of white adipose tissue. The action of adipokines could be altered during neurodegenerative events and might feedback to contribute to neurodegeneration. ${ }^{27}$ Age-related reduction of muscle mass and strength is a major public health concern in older persons. The association between muscle and cognition could mainly be derived from muscle strength. Boyle $e t$ $a l^{28}$ found that high muscle strength decreased the risk of alzheimer's disease (AD), and Chen et $a l^{29}$ had similar findings.

It is noteworthy to mention that previous studies have reported high-fat diet exacerbates cognitive decline. ${ }^{30} 31$ Amyloid deposition and cerebral microvasculature dysfunction are the most discussed mechanisms in relevant studies. ${ }^{30-33}$ These findings suggest further studies are needed to explore the mechanisms that underlie the association between obesity and cognitive impairment.

Some limitations of the present study should be noted. One limitation is that high-fat diet, which is an important influence factor for cognitive function as mentioned above, was not included in this study. It is probable that high-fat diet leads to central obesity with high BMI and WHR among Chinese elderly. Further studies are needed to explore the relationship within diet, WHR and cognitive impairment. Besides, caution would be needed when generalising the present findings, as our results were based on a cross-sectional study.

\section{CONCLUSIONS}

Higher WHR significantly increases the risk of cognitive impairment among the elderly with BMI $>25.3 \mathrm{~kg} / \mathrm{m}^{2}$. The results of this study suggest that it is of benefit to the elderly with high BMI to control WHR.

Acknowledgements We acknowledge the invaluable contributions made by all the interviewers of the Zhejiang Ageing and Health Cohort Study.

Contributors JL, RY, TZ, QC, XY, YZ, FL, XW, FH and CY participated in the design of the study, collection of data, data cleaning. TZ, RY, YZ, FL, XW and CY conducted the statistical analyses. TZ wrote the manuscript. RY, QC, XY and JL contributed to the interpretation of the results and revised the manuscript critically. All authors approved the final version of the manuscript.

Funding This work was supported by Zhejiang Provincial Medical and Health Science and Technology Project (2015KYB081, 2017KY285, 2017RC018), Zhejiang Provincial Natural Science Foundation of China (Q19H260002), and Science and Technology Bureau of Yuhuan (201731).

Competing interests None declared.

Patient consent Obtained.

Ethics approval Ethics Committee of Zhejiang Provincial Center for Disease Control and Prevention.

Provenance and peer review Not commissioned; externally peer reviewed.

Data sharing statement Data are not publicly available due to local ethical restrictions.

Open access This is an open access article distributed in accordance with the Creative Commons Attribution Non Commercial (CC BY-NC 4.0) license, which permits others to distribute, remix, adapt, build upon this work non-commercially, and license their derivative works on different terms, provided the original work is properly cited, appropriate credit is given, any changes made indicated, and the use is non-commercial. See: http://creativecommons.org/licenses/by-nc/4.0/.

\section{REFERENCES}

1. Herrera AC, Prince M, Knapp M, et al. World Alzheimer Report 2016: Improving healthcare for people with dementia Coverage, quality and costs now and in the future, 2016.

2. Chan KY, Wang W, Wu JJ, et al. Epidemiology of Alzheimer's disease and other forms of dementia in China, 1990-2010: a systematic review and analysis. Lancet 2013;381:2016-23.

3. Nie H, Xu Y, Liu B, et al. The prevalence of mild cognitive impairment about elderly population in China: a meta-analysis. Int J Geriatr Psychiatry 2011;26:558-63. 
4. Qizilbash N, Gregson J, Johnson ME, et al. BMI and risk of dementia in two million people over two decades: a retrospective cohort study. Lancet Diabetes Endocrinol 2015;3:431-6.

5. Tolppanen AM, Ngandu T, Kåreholt I, et al. Midlife and late-life body mass index and late-life dementia: results from a prospective population-based cohort. J Alzheimers Dis 2014;38:201-9.

6. Monda V, La Marra M, Perrella R, et al. Obesity and brain illness: from cognitive and psychological evidences to obesity paradox. Diabetes Metab Syndr Obes 2017;10:473-9.

7. Tikhonoff $\mathrm{V}$, Casiglia $\mathrm{E}$, Guidotti $\mathrm{F}$, et al. Body fat and the cognitive pattern: A population-based study. Obesity 2015;23:1502-10.

8. Kim S, Kim Y, Park SM. Body mass index and decline of cognitive function. PLoS One 2016;11:e0148908.

9. Gunstad J, Lhotsky A, Wendell CR, et al. Longitudinal examination of obesity and cognitive function: results from the Baltimore longitudinal study of aging. Neuroepidemiology 2010;34:222-9.

10. Gallucci M, Mazzuco S, Ongaro F, et al. Body mass index, lifestyles, physical performance and cognitive decline: The "Treviso Longeva (Trelong)" study. J Nutr Health Aging 2013;17:378-84.

11. Besser LM, Gill DP, Monsell SE, et al. Body mass index, weight change, and clinical progression in mild cognitive impairment and Alzheimer disease. Alzheimer Dis Assoc Disord 2014;28:36-43.

12. Smith $E$, Hay $P$, Campbell $L$, et al. A review of the association between obesity and cognitive function across the lifespan: implications for novel approaches to prevention and treatment. Obes Rev 2011;12:740-55.

13. Benito-León J, Mitchell AJ, Hernández-Gallego J, et al. Obesity and impaired cognitive functioning in the elderly: a population-based cross-sectional study (NEDICES). Eur J Neurol 2013;20:899-e77.

14. Turcato E, Bosello O, Di Francesco V, et al. Waist circumference and abdominal sagittal diameter as surrogates of body fat distribution in the elderly: their relation with cardiovascular risk factors. Int J Obes Relat Metab Disord 2000;24:1005-10.

15. Villareal DT, Apovian CM, Kushner RF, et al. Obesity in older adults: technical review and position statement of the American Society for Nutrition and NAASO, The Obesity Society. Am J Clin Nutr 2005:82:923-34.

16. Sharma S, Batsis JA, Coutinho T, et al. Normal-weight central obesity and mortality risk in older adults with coronary artery disease. Mayo Clin Proc 2016;91:343-51.

17. Sahakyan KR, Somers VK, Rodriguez-Escudero JP, et al. Normalweight central obesity: implications for total and cardiovascular mortality. Ann Intern Med 2015;163:827-35.

18. Zhengyu W, mingyuan Z. Application of Chinese version of MiniMental State examination (MMSE). Shanghai Archives of Psychiatry 1989;3:108-11.
19. Li FD, He F, Chen TR, et al. Reproductive history and risk of cognitive impairment in elderly women: a cross-sectional study in eastern China. J Alzheimers Dis 2016;49:139-47.

20. Kroenke K, Spitzer RL, Williams JB. The PHQ-9: validity of a brief depression severity measure. J Gen Intern Med 2001;16:606-13.

21. Zhou Y, Flaherty JH, Huang CQ, et al. Association between body mass index and cognitive function among Chinese nonagenarians/ centenarians. Dement Geriatr Cogn Disord 2010;30:517-24.

22. Sabia S, Nabi H, Kivimaki M, et al. Health behaviors from early to late midlife as predictors of cognitive function: The Whitehall II study. Am $J$ Epidemiol 2009;170:428-37.

23. Dahl AK, Hassing LB, Fransson El, et al. Body mass index across midlife and cognitive change in late life. Int $J$ Obes 2013;37:296-302.

24. Sturman MT, de Leon CF, Bienias JL, et al. Body mass index and cognitive decline in a biracial community population. Neurology 2008;70:360-7.

25. Arvanitakis Z, Capuano AW, Bennett DA, et al. Body mass index and decline in cognitive function in older black and white persons. $J$ Gerontol A Biol Sci Med Sci 2018;73:198-203.

26. Wang F, Zhao M, Han Z, et al. Association of body mass index with amnestic and non-amnestic mild cognitive impairment risk in elderly. BMC Psychiatry 2017;17:334.

27. Kiliaan AJ, Arnoldussen IA, Gustafson DR. Adipokines: a link between obesity and dementia? Lancet Neurol 2014;13:913-23.

28. Boyle PA, Buchman AS, Wilson RS, et al. Association of muscle strength with the risk of Alzheimer disease and the rate of cognitive decline in community-dwelling older persons. Arch Neurol 2009;66:1339.

29. Chen WL, Peng TC, Sun YS, et al. Examining the association between quadriceps strength and cognitive performance in the elderly. Medicine 2015;94:e1335.

30. Thériault P, ElAli A, Rivest S. High fat diet exacerbates Alzheimer's disease-related pathology in APPswe/PS1 mice. Oncotarget 2016;7:67808-27.

31. Lin B, Hasegawa Y, Takane $K$, et al. High-fat-diet intake enhances cerebral amyloid angiopathy and cognitive impairment in a mouse model of alzheimer's disease, independently of metabolic disorders. J Am Heart Assoc 2016;5:e003154.

32. Pimentel-Coelho PM, Rivest S. The early contribution of cerebrovascular factors to the pathogenesis of Alzheimer's disease. Eur J Neurosci 2012;35:1917-37.

33. Zlokovic BV. Neurovascular pathways to neurodegeneration in Alzheimer's disease and other disorders. Nat Rev Neurosci 2011;12:723-38. 
Corrections: Body mass index, waist-to-hip ratio and cognitive function among Chinese elderly: a cross-sectional study

Zhang $\mathrm{T}$, Yan $\mathrm{R}$, Chen $\mathrm{Q}$ et al. Body mass index, waist-to-hip ratio and cognitive function among Chinese elderly: a cross-sectional study. BMJ Open 2018;8:e022055. doi: 10.1136/bmjopen-2018-022055.

This article was previously published with missing equal contributor statement.

Tao Zhang, Rui Yan, and Qifeng Chen, contributed equally to this work.

Open access This is an open access article distributed in accordance with the Creative Commons Attribution Non Commercial (CC BY-NC 4.0) license, which permits others to distribute, remix, adapt, build upon this work non-commercially, and license their derivative works on different terms, provided the original work is properly cited, appropriate credit is given, any changes made indicated, and the use is non-commercial. See: http://creativecommons.org/licenses/by-nc/4.0/.

(C) Author(s) (or their employer(s)) 2018. Re-use permitted under CC BY-NC. No commercial re-use. See rights and permissions. Published by BMJ.

BMJ Open 2018;8:e022055corr1. doi:10.1136/bmjopen-2018-022055corr1

A Check for updates 